\title{
Chronic Cystoisospora belli infection in an immunocompetent Myanmar refugee - microscopy is not sensitive enough
}

\author{
Sze-Ann Woon ${ }^{1,4^{*}}$, Rongchang Yang ${ }^{2}$, Una Ryan², Peter Boan ${ }^{1}$ and David Prentice ${ }^{3}$
}

\begin{abstract}
Background: Cystoisosporiasis is an opportunistic infection seen more commonly in patients with acquired immunodeficiency syndrome. Although uncommon, Cystoisospora infection can occur in immunocompetent individuals but tend to be benign and self-limiting. Chronic infection however, has been described but diagnosis can often be challenging and requires a high clinical index of suspicion.

Case presentation: We present a case of delayed diagnosis of Cystoisospora belli (C. belli) in an immunocompetent 28-year-old refugee from Myanmar. She had a history of chronic diarrhea where exhaustive investigations over many years failed to reveal a diagnosis. Cystoisospora belli cysts were finally detected in stool 4 years after investigation commenced, and PCR testing on stored colon biopsies amplified a molecular product with $99 \%$ sequence homology to C. belli. The patient improved promptly with trimethoprim-sulfamethoxazole treatment.

Conclusion: In the appropriate clinical context we suggest molecular testing for C. belli or an empirical therapeutic trial.
\end{abstract}

\section{Background}

C. belli is an obligate intracellular coccidian parasite and is a recognized agent of enteric disease. It has a global distribution with predominance in the tropics and subtropics [1]. Intestinal parasitic infection is common in Myanmar, as shown in a screening study of Myanmar migrant workers, demonstrating intestinal parasites in $62.3 \%$ of migrants [2]. However, there is no data in the literature regarding rates of C. belli in Myanmar. Cystoisospora infection is characterized by watery diarrhea, sometimes with fever, abdominal pain, nausea and vomiting. Peripheral eosinophilia is commonly noted as distinct from other coccidian parasites. Immunosuppressed patients present with more severe diarrhea and can have extra-intestinal manifestations whereas infection in immunocompetent patients tends to be selflimiting. Chronic infection affecting immunocompetent individuals can occur but can be challenging to diagnose owing to the intermittent shedding of the oocysts and

\footnotetext{
*Correspondence: Sze-Ann.Woon@health.wa.gov.au

'Department of Microbiology and Infectious Disease, PathWest Laboratory

Medicine WA and Royal Perth Hospital, Perth, Australia

${ }^{4}$ Department of Infectious Disease, National University Hospital, 5 Lower Kent

Ridge Road, Singapore 119074, Singapore

Full list of author information is available at the end of the article
}

low sensitivity of standard microscopic techniques in detecting the cysts. This can potentially lead to delayed diagnosis and treatment as in the case of our patient where the diagnosis was eventually made after 4 years of extensive and repeated investigations by PCR testing of colonic biopsies.

\section{Clinical record}

A 28-year-old female from Myanmar was referred for investigation of diarrhea in 2010, shortly after arrival as a refugee to Perth, Western Australia. Diarrhea up to 10 times per day had been ongoing since age 8 , occasionally associated with nausea, vomiting or abdominal pain but without steatorrhea, blood in the stool or fevers. Low body mass index of $16 \mathrm{~kg} / \mathrm{m}^{2}$ was persistent despite attempts to gain weight. Hospital admission several times per year was required due to volume depletion and hypokalemia.

Differential white cell count was significant for persistent eosinophilia, usually $1-2 \times 10^{9}$ cells/ $\mathrm{L}(\mathrm{N}$ 0.00- $0.50 \times$ $10^{9}$ cells/L), with a peak level of $6.7 \times 10^{9}$ cells/L. IgE was also markedly elevated ( $4100 \mathrm{KU} / \mathrm{L}, \mathrm{N}<210 \mathrm{KU} / \mathrm{L}])$. MRI of the pancreas and biliary tree, CT abdomen, CT enteroclysis, autoimmune screen, coeliac antibodies, 
several upper GI endoscopies and colonscopies were all unremarkable. Serology for HIV, Schistosoma and Strongyloides infections was negative. Histopathology of endoscopic biopsy samples demonstrated mild duodenitis and colitis characterized by increased numbers of plasma cells and lymphocytes. Granulomas were absent, and there were normal numbers of eosinophils. Parasites were not detected in 10 stool samples from the years 2010-2012, specifically examined for parasites including Cryptosporidium, Cyclospora and Cystoisospora by centrifugation (500 $\mathrm{x}$ g for $10 \mathrm{~min}$ ), concentrated wet mount and modified safranin stain. Microsporidia were not detected in 3 stools examined by modified trichrome stain. Charcot-Leyden crystals were noted in a number of stool samples. Diarrhea persisted despite empirical treatment of intestinal parasites with metronidazole (400 $\mathrm{mg}$ orally, 8-hourly for 5 days) and albendazole (400 mg orally, 12-hourly for 3 days).

Finally C. belli oocysts were detected in a stool sample in 2014. Stool not being available for molecular testing, we then tested by PCR stored paraffin sections of colon biopsies obtained at colonoscopy in 2012, detecting $C$. belli in 3 of 5 biopsies. We deparaffinised with xylene, and extracted with digestion buffer $(10 \mathrm{mmol} / \mathrm{L}$ Tris$\mathrm{HCl}, 50 \mathrm{mmol} / \mathrm{L} \mathrm{KCl}, 1.5 \mathrm{mmol} / \mathrm{L} \mathrm{MgCl} 2,0.5$ \% Tween 20) plus proteinase $\mathrm{K} 20 \mathrm{mg} / \mathrm{mL}$. Amplification of a $404 \mathrm{bp}$ region of the Cystoisospora ribosomal RNA (rRNA) internal transcribed spacer (ITS) locus by nested PCR from the 5 DNA samples was conducted as described by Johnson et al. [3] The 5 samples were also amplified at the mitochondrial cytochrome oxidase gene (COI) locus by a nested PCR as described by Dolnik et al. [4] and Yang et al. [5] Secondary PCR products were gel purified using an in house filter tip method without any further purification for downstream sequencing as previously described [6]. The PCR amplicons were sequenced with the internal ITS and COI PCR primers respectively, in both directions using a BigDye Terminator Kit (v3.1) (Life Technologies, Foster City, California). The results of the sequencing reactions were analysed and edited using Finch $T V^{\circ} \mathrm{v}$ 1.4.0 [7]. and compared to existing Cystoisospora spp. ITS and COI sequences on GenBank using BLAST searches and aligned with reference species from GenBank using Clustal W [8]. Phylogenetic analyses were conducted for Cystoisospora spp. at the ITS and COI loci with additional isolates from GenBank. Distance estimation was conducted using TREECON [9], based on evolutionary distances calculated with the Tamura-Nei model and grouped using Neighbour-Joining. Maximum Likelihood (ML) analyses were conducted using MEGA version 6 (MEGA6: Molecular Evolutionary Genetics Analysis software, Arizona State University, Tempe, Arizona, USA). Bootstrap analyses were conducted using 1000 replicates to assess the reliability of inferred tree topologies. Three of the five samples were positive by PCR at the ITS locus. Of these three, there was sufficient DNA from two of these positives for sequencing analysis. Both samples produced $100 \%$ identical 414 bp sequences that were $99.5 \%$

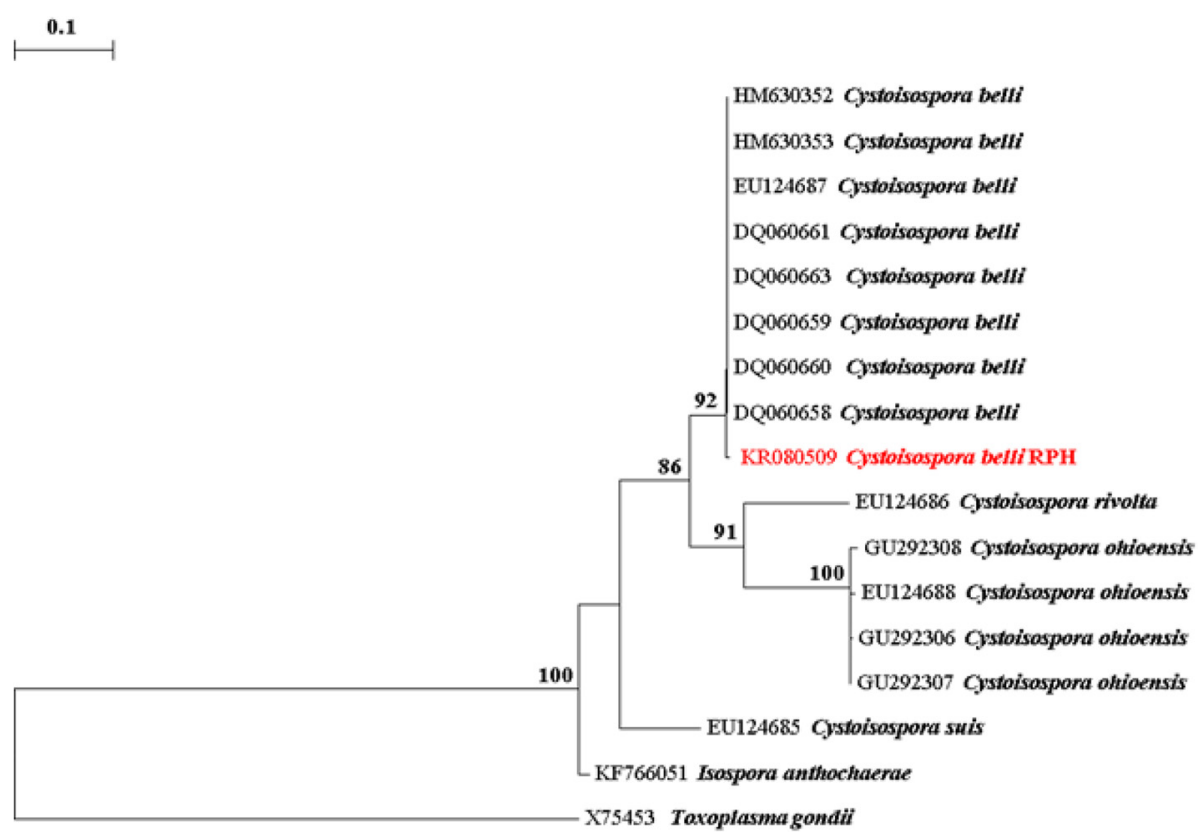

Fig. 1 Evolutionary relationships of Cystoisospora belli inferred by distance analysis of ITS rRNA sequences. Percentage support (>70 \%) from 1000 pseudoreplicates is indicated at the left of the supported node 
identical to C. belli from other human-derived Cystoisospora isolates available from GenBank (accession numbers: MH630353, EU124687, HM630352 and DQ065658 -DQ065663) (Fig. 1-Distance tree shown). At the COI locus, two of the five samples were positive by PCR. Sequences were obtained from both 223 bp amplicons. Unfortunately, no $C$. belli $\mathrm{COI}$ sequences were available in GenBank and therefore the sequences obtained in the present study exhibited $85.5 \%$ similarity to C. felis (GenBank accession number: JN473253) (Fig. 2-Distance tree shown). This is the first report of sequence data for $C$. belli at the COI locus. Distance and ML analysis produced identical tree topologies (data not shown).

There was transient resolution of diarrhea with trimethoprim-sulfamethoxazole (TMP-SMX) one double strength tablet (160 mg TMP/800 mg SMX) twice daily for 10 days, with complete resolution of symptoms with TMP-SMX retreatment for one month at the same daily dose. Microscopic examinations of 12 subsequent stool samples were negative with normalization of eosinophilia and no recurrence of diarrhea.

\section{Discussion}

Chronic and recurrent infection in immunocompetent patients such as occurred in our patient have been previously described [10]. Jongwutiwes et al. [11] report a 54 year old Thai man with a 10 year history of intermittent diarrhea. Several initial stools were negative for parasites by microscopy, with $C$. belli oocysts detected in stool and jejunal biopsy 3 years after initial symptoms. He responded promptly to TMP-SMX however needed several courses before diarrhea was cured. Kim et al. [12] report a 2 year history of diarrhea and $35 \mathrm{~kg}$ weight loss in a 70 year old alcoholic Korean man. There was prominent peripheral eosinophilia, and stool examination on 3 occasions did not detect parasites. The diagnosis of chronic $C$. belli infection was finally made by demonstration of a number of the parasite stages in jejunal biopsy. The patient was successfully treated with 1 month of TMP-SMX.

Diagnosis of Cystoisospora infection can be challenging owing to the intermittent and low grade shedding of oocysts, as demonstrated in our case and also the other

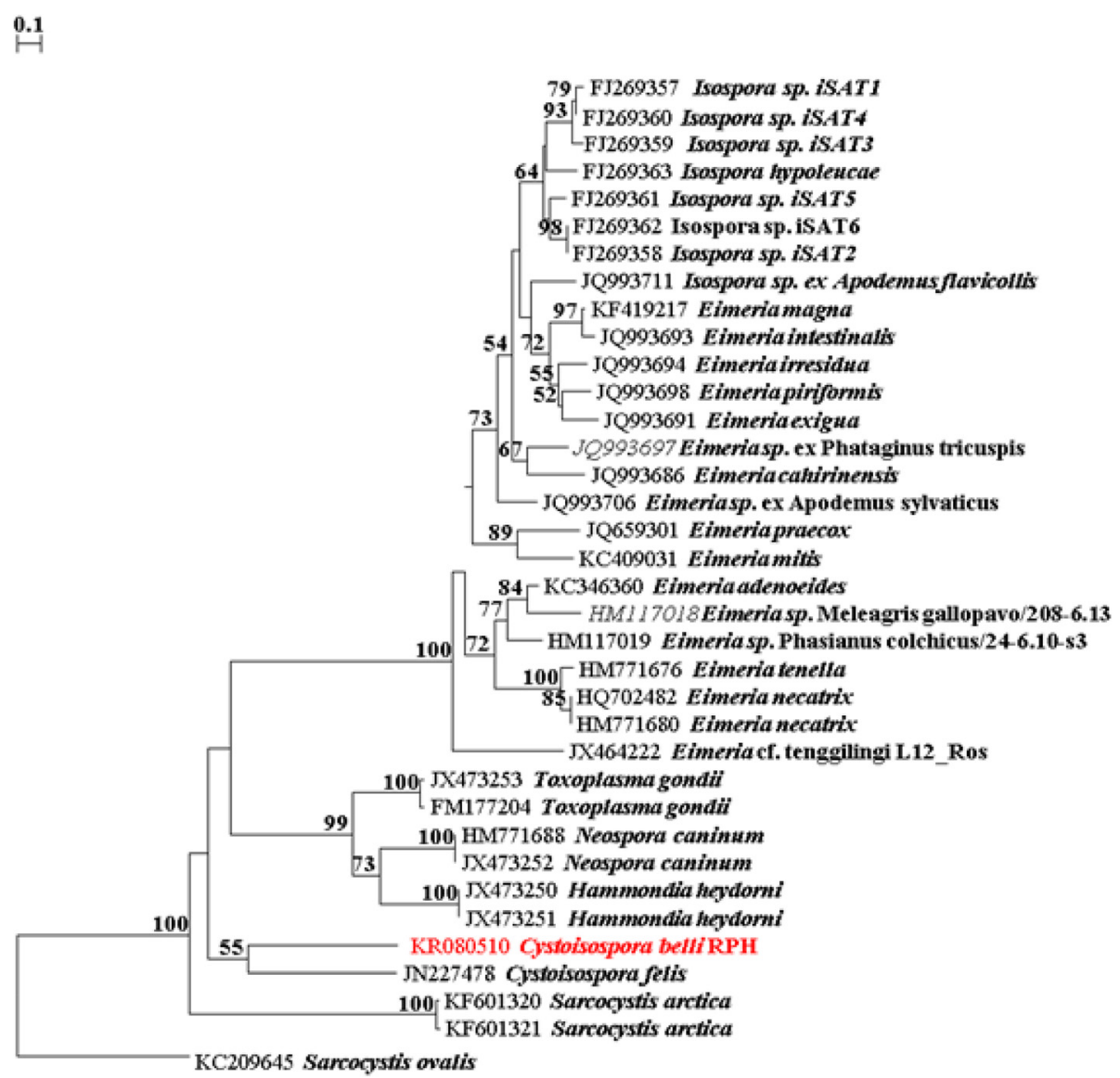

Fig. 2 Evolutionary relationships of Cystoisospora belli inferred by distance analysis of COI sequences. Percentage support (>70 \%) from 1000 pseudoreplicates is indicated at the left of the supported node 
reported cases of chronic infection. The sensitivity of any microscopic technique is unknown without an optimal gold standard for diagnosis. In a study comparing stains for the detection $C$. belli, auto-fluorescence and auramine-O staining had $100 \%$ sensitivity and specificity compared to the modified Zeihl-Neelsen stain, while wet mount with iodine staining showed $54 \%$ sensitivity [13]. Similarly, another study showed auto-fluorescent staining detected C. belli in twice as many stools as the iodine stain [14]. Repeated sampling and examination by trained microscopists using specific methods is suggested [7], however molecular testing [15] may be more sensitive as has been demonstrated for Cryptosporidium PCR compared to microscopy $[16,17]$. In evaluating a multiplex PCR to detect Cystoisospora, Cyclospora and Microsporidia in stool, Taniuchi et al demonstrated $93 \%$ sensitivity of the Cystoisospora PCR assay compared to microscopy (26 PCR positive of 28 microscopy positive). 14 of the total 208 microscopy negative samples tested positive by PCR. Some of the available discrepant samples tested positive by an alternative singleplex real-time PCR C. belli assay, suggesting higher sensitivity of molecular techniques compared to microscopy [18]. A separate study of a real-time PCR assay found it to be at least as sensitive (100\% sensitive, 21 samples) as microscopy for the detection of C. belli. C. belli PCR was negative on all 147 negative controls [19]. Murphy et al. [20] report a 44 year old HIV infected Mexican with diarrhea and weight loss. Stool microscopy and ileal biopsy did not reveal an infectious agent, but PCR of the ileal biopsy material using universal primers (ITS1, ITS2, 28S rRNA genes) detected an ITS1 product, which by molecular sequencing had good homology with reference sequences of $C$. belli. In the present study, nested PCR and sequence analysis at two loci was used to detect and confirm $C$. belli in three of five paraffinembedded colon biopsy specimens.

\section{Conclusion}

We present the case of a refugee with chronic diarrhea, Charcot-Leyden crystals in the stool, and peripheral eosinophilia. Chronic intestinal parasitic infection was suspected but could not be proven until C. belli was detected on the $11^{\text {th }}$ stool examination. We deduced that C. belli was the cause of chronic diarrhea due to high epidemiological risk, persistent eosinophilia, positive molecular testing on stored biopsies, response to TMPSMX, and absence of an alternative diagnosis despite exhaustive investigation. We conclude that standard microscopic methods to detect $C$. belli were not sensitive enough to detect the pathogen. Potentially there are a large number of undiagnosed cases worldwide, where molecular testing should be pursued or empirical treatment considered.

\section{Ethics approval and consent to participate}

\author{
Not applicable.
}

\section{Consent for publication}

Written informed consent was obtained from the patient for publication of this case report. A copy of the written consent is available for review by the Editor of this journal.

\section{Availability of data and materials}

Phylogenetic material deposited in Genbank (GenBank accession numbers: KR0805009 for ITS sequences and KR0805010 for COI sequences) and TreeBase (ID 19089).

\section{Abbreviations \\ CT: computed tomography; DNA: deoxyribonucleic acid; Gl: gastrointestinal; HIV: human immunodeficiency virus; IgE: immunoglobulin E; MRI: magnetic resonance imaging; PCR: polymerase chain reaction; RNA: ribonucleic acid.}

\section{Competing interests}

The authors declare that they have no competing interests.

\section{Authors' contributions \\ SW, PB and DP cared for the patient and prepared the manuscript. RY and UR performed the PCR analysis and contributed to the manuscript. All authors read and approved the final manuscript.}

\section{Acknowledgements}

None.

\section{Funding}

Not applicable.

\section{Author details}

${ }^{1}$ Department of Microbiology and Infectious Disease, PathWest Laboratory Medicine WA and Royal Perth Hospital, Perth, Australia. ${ }^{2}$ School of Veterinary and Life Sciences, Murdoch University, Perth, Australia. ${ }^{3}$ Department of Internal Medicine, Royal Perth Hospital, Perth, Australia. ${ }^{4}$ Department of Infectious Disease, National University Hospital, 5 Lower Kent Ridge Road, Singapore 119074, Singapore.

Received: 16 October 2015 Accepted: 10 May 2016

Published online: 21 May 2016

\section{References}

1. Lindsay DS, Dubey JP, Blagburn BL. Biology of Isospora spp. from humans, nonhuman primates, and domestic animals. Clin Microbiol Rev. 1997;10(1): 19-34.

2. Nuchprayoon S, Sansprasert V, Kaewzaithim S, Saksirisampant W. Screening for intestinal parasitic infections among Myanmar migrant workers in Thai food industry: a high-risk transmission. J Immigr Minor Health. 2009;11:115-21.

3. Johnson J, Samarasinghe B, Buddle R, et al. Molecular identification and prevalence of Isospora sp. in pigs in Western Australia using a PCR-RFLP assay. Exp Parasitol. 2008;120:191-3.

4. Dolnik OV, Palinauskas V, Bensch S. Individual oocysts of Isospora (Apicomplexa: Coccidia) parasites from avian faeces: from photo to sequence. J Parasitol. 2009;95:169-74.

5. Yang R, Brice B, Bennett M D, Ryan U. Novel Eimeria sp. isolated from a King's skink (Egernia kingii) in Western Australia. Exp Parasitol. 2013a;133: 162-165.

6. Yang R, Murphy C, Song Y, et al. Specific and quantitative detection and identification of Cryptosporidium hominis and C. parvum in clinical and environmental samples. Exp Parasitol. 2013b;135:142-147.

7. Geospiza's FinchTV. Available at http://finchtv.software.informer.com/1.4/.

8. Multiple Sequence Alignment by CLUSTALW. Available at http://www. genome.jp/tools/clustalw/. 
9. Van de Peer Y, De Wachter R. TREECON for Windows: a software package for the construction and drawing of evolutionary trees for the Microsoft Windows environment. Comp Appl Biosci. 1994;10:569-70.

10. Legua P, Seas C. Cystoisospora and cyclospora. Curr Opin Infect Dis. 2013; 26(5):479-83.

11. Jongwutiwes S, Sampatanukul P, Putaporntip C. Recurrent isosporiasis over a decade in an immunocompetent host successfully treated with pyrimethamine. Scand J Infect Dis. 2002;34(11):859-62.

12. Kim MJ, Kim WH, Jung HC, Chai JW, Chai JY. Isospora belli Infection with Chronic Diarrhea in an Alcoholic Patient. Korean J Parasitol. 2013;51(2):207-12.

13. Ahmed NH, Chowdhary A. Comparison of different methods of detection of enteric pathogenic protozoa. Indian J Med Microbiol. 2013;31(2):154-60.

14. Bialek R, Binder N, Dietz K, Knobloch J, Zelck UE. Comparison of autofluorescence and iodine staining for detection of Isospora belli in feces. Am J Trop Med Hyg. 2002:67(3):304-5.

15. Verweij JJ, Stensvold CR. Molecular testing for clinical diagnosis and epidemiological investigations of intestinal parasitic infections. Clin Microbiol Rev. 2014;27(2):371-418.

16. Ryan UM, Bath C, Robertson I, et al. Sheep may not be an important zoonotic reservoir for Cryptosporidium and Giardia parasites. Appl Environ Microbiol. 2005;71(9):4992-7.

17. Bruijnesteijn van Coppenraet LE, Wallinga JA, Ruijs GS, Bruins MJ, Verweij JJ. Parasitological diagnosis combining an internally controlled real-time PCR assay for the detection of four protozoa in stool samples with a testing algorithm for microscopy. Clin Microbiol Infect. 2009;15:869-74.

18. Taniuchi M, Verweij JJ, Sethabutr O, et al. Multiplex polymerase chain reaction method to detect Cyclospora, Cystoisospora, and microsporidia in stool samples. Diag Microbiol Infect Dis. 2011;71:386-90.

19. ten Hove RJ, van Lieshout L, Brienen EA, et al. Real-time polymerase chain reaction for detection of Isospora belli in stool samples. Diag Microbiol Infect Dis. 2008;61:280.

20. Murphy SC, Hoogestraat DR, SenGupta DJ, et al. Molecular diagnosis of cystoisosporiasis using extended-range PCR screening. J Mol Diag. 2011;13 359-62.

\section{Submit your next manuscript to BioMed Central and we will help you at every step:}

- We accept pre-submission inquiries

- Our selector tool helps you to find the most relevant journal

- We provide round the clock customer support

- Convenient online submission

- Thorough peer review

- Inclusion in PubMed and all major indexing services

- Maximum visibility for your research

Submit your manuscript at www biomedcentral.com/submit

) Biomed Central 